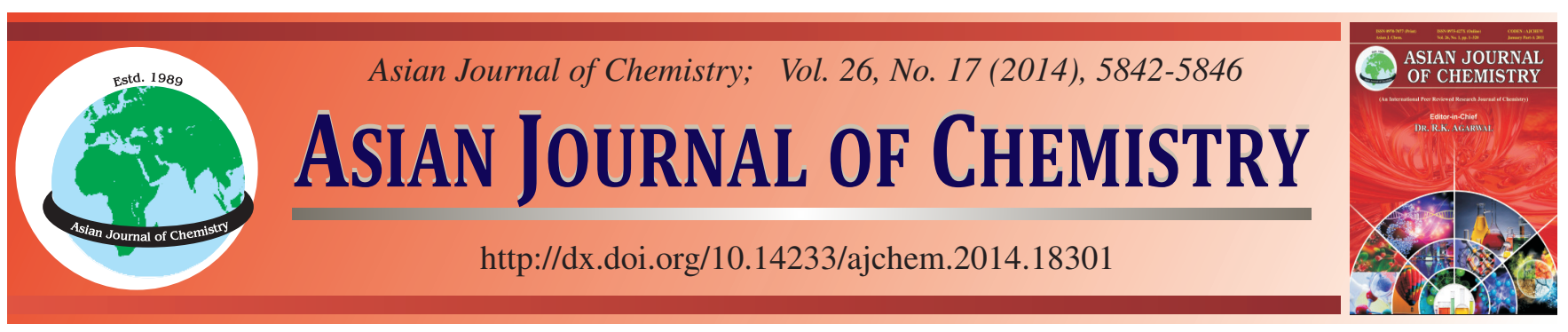

\title{
Study of Aluminum Foam Sandwiched Bonnet Based on Pedestrian Protection and Orthogonal Design $\dagger$
}

\author{
NA YANG ${ }^{1}$, Guifan ZhaO ${ }^{1}$, Congsheng $\mathrm{Li}^{2}{ }^{2,}, \mathrm{HuA} \mathrm{Li}^{3}$ and JiAnFEng WANG ${ }^{1}$
}

${ }^{1}$ School of Computer Science and Technology, Harbin Institute of Technology, Weihai, P.R. China

${ }^{2}$ School of Automotive Engineering, Harbin Institute of Technology, Weihai, P.R. China

${ }^{3}$ School of Mechatronics Engineering, Harbin Institute of Technology, Harbin, P.R. China

*Corresponding author: Fax: +86 631 5672276; Tel: +86 631 5687701; E-mail: lisheng51998@163.com

\begin{abstract}
In order to reduce head injuries during vehicle-to-pedestrian impacts, the aluminum foam sandwiched (AFS) bonnet was designed and analyzed. Firstly, the finite element models of the pedestrian-engine bonnet were established according to the statutes of the EEVC WG17. The acceleration curve and head injury criterion (HIC) of each test point were obtained. Secondly, the original engine bonnet materials were changed to AFS materials. The parameters of the new engine bonnet were preliminarily designed. Referring to head protection, the material parameter combinations were studied by using an orthogonal experimental design method. Finally, a weight analysis was carried out. The results indicated that the new bonnet could protect a pedestrian's head effectively and also reduce the weight of the vehicle to improve fuel economy.
\end{abstract}

Keywords: Engine bonnet, Aluminum foams, Pedestrian protection, Experiment design, Range analysis.

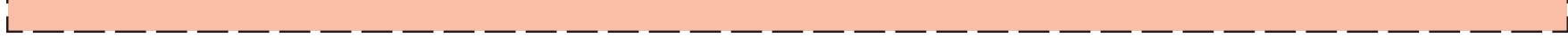

\section{INTRODUCTION}

A survey of a large number of traffic accidents shows that the fronts of vehicles impact pedestrians and account for $70-85 \%$ of the total number of traffic collisions. In vehicleto-pedestrian accidents, the percentage of deaths caused by head injuries was $64 \%$. In order to reduce head injuries in vehicle-to-pedestrian impacts, The European Union, Japan and Australia have enacted regulations related to pedestrian protection. In October 2009, China issued "The Protection of Motor Vehicles for Pedestrians in the Event of a Collision," which specifies the pedestrian protection regulations standard and put it into effect in July 2010.

To reduce the injuries to pedestrians and protect them effectively, not only should a relative regulation be issued, but also vehicle safety should be improved. At this time, one method is developed to improve the structure is to reduce the collision speed; another is to reduce the stiffness of the material of the engine bonnet and improve the energy absorption capability ${ }^{3,4}$. However, due to the limitations of the vehicle structure and weight restrictions, there is not very much potential to improve the bonnet structure. Nonetheless, studying a new bonnet material could solve the problem of pedestrian protection and at the same time work out the predicament of weight issues. Research of new materials has become the new trend in the field of vehicle passive safety.

Aluminum foam sandwiched (AFS) which has low density, high intensity, is easy to manufacture ${ }^{5}$ and has good energy absorption capabilities. BMW, Mercedes-Benz and Honda have all applied aluminum foam material to fill components such as bumpers to achieve the goal of buffer energy absorption ${ }^{6}$.

\section{Models}

Finite element models of head form impactor-vehicle: The impact model was established according to the EEVC

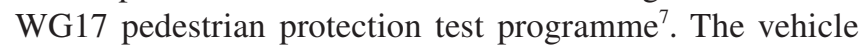
model was an existing vehicle on the market which had 226 components which included 261,674 nodes, 250,394 elements and a total mass of $2,620 \mathrm{~kg}$. The free-motion head model had 2,662 nodes and 9,852 elements, the materials of which are shown in Table 1. The head-vehicle impact model is shown in Fig. 1(a). The head model is shown in Fig. 1(b).

Finite element model of the aluminum foam sandwiched bonnet: When the finite element model of the AFS bonnet was established, the top and bottom panels made up 


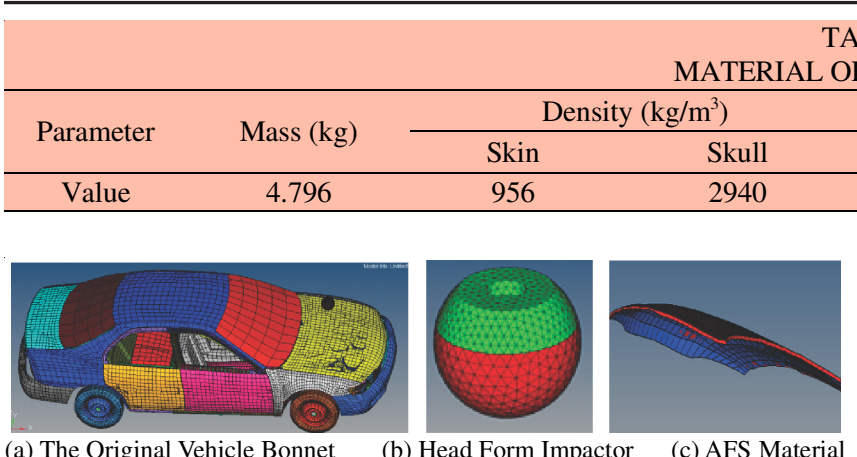

Fig. 1. Finite element models

the shell and the filling was solid 3D elements. To simulate the contact, the 2D elements were extracted from the 3D solid elements. The model of the AFS bonnet is shown in Fig. 1(c).

Selection of the test points: The EEVC WG17 regulates that the adult head test areas should measure 1500-2100 mm wrap around distance (WAD). In the transverse direction, the middle area is divided into three parts, which is shown in Fig. 2.

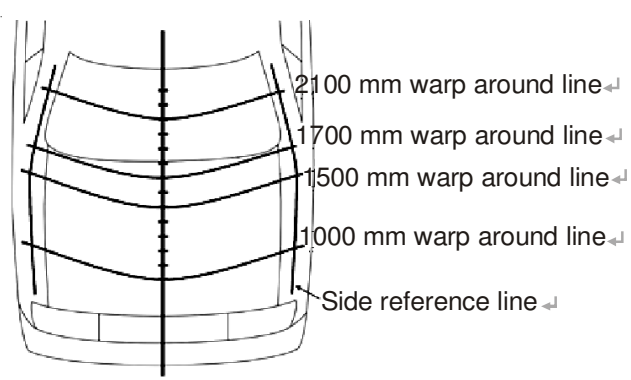

Fig. 2. Partition of adult head test areas

According to the EEVC WG17, three test points in the right, left and middle of the bonnet should be chosen, for a total of nine test points. Generally, the areas which have the potential to cause serious injuries to the head are in the sides, the upper part of the engine, the upper sides of the bonnet suspension and radiator and the upper portion of the inner bonnet structure ${ }^{8}$. The chosen test points are shown in Fig. 3 and Table-2.

Simulation analysis of head form impacting the original bonnet: The EEVC WG17 regulates that the impact angle be $65 \pm 2^{\circ}$ between the head form and the ground, with an impact velocity of $9.7 \pm 0.2 \mathrm{~m} / \mathrm{s}$.

Head injury criterion (HIC): At present, the most widely used standard for pedestrian head injuries is the head injury criterion (HIC). The federal motor vehicle safety standards
ABLE-1

(GPa)

Elasticity modulus of Poisson's ratio of skull $(\mathrm{GPa})$ skull

0.25

30

0.33
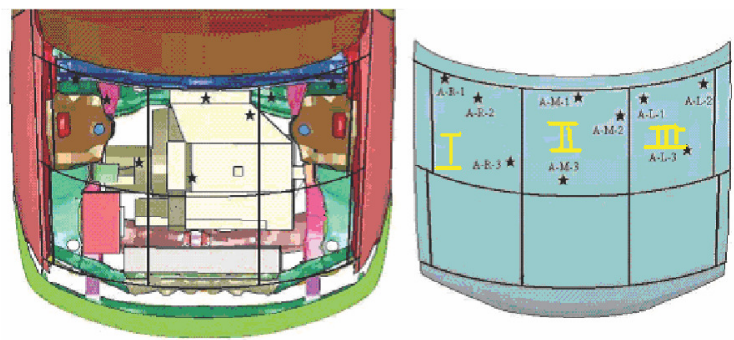

Fig. 3. Test points

(FMVSS) put forth the calculation method of the HIC as follows:

$$
\mathrm{HIC}=\left[\frac{1}{\mathrm{t}_{2}-\mathrm{t}_{1}} \int_{\mathrm{t}_{1}}^{\mathrm{t}_{2}} \mathrm{a}(\mathrm{t}) \mathrm{dt}\right]^{2.5}\left(\mathrm{t}_{2}-\mathrm{t}_{1}\right)
$$

where ' $a$ ' is the resultant acceleration as a multiple of ' $\mathrm{g}$ ' and ' $t_{1}$ ' and ' $t_{2}$ ' are the two time instants when the value of HIC is at maximum. Actually, the value of ' $\mathrm{t}_{1}-\mathrm{t}_{2}$ ' was $15 \mathrm{~ms}$ or $36 \mathrm{~ms}$. When the HIC is bigger than 1000, the incidence of AIS $3+$ head injuries is $20 \%$.

Considering the difference between the free-motion head and the Hybrid III dummy head, a linear regression equation called $\mathrm{HIC}_{\mathrm{d}}$ was used to adjust HIC, shown as follows:

$$
\mathrm{HIC}_{\mathrm{d}}=0.75446[\mathrm{HIC}]+166.4
$$

Injury analysis of original vehicle to head: The impact of the head form to the bonnet was simulated in each test point using LS-DYNA. The HIC, $\mathrm{HIC}_{\mathrm{d}}$ and the maximum acceleration $\mathrm{a}_{\max }$ are shown in Table-3.

Injury analysis of AFS material vehicle to head: Initially, steel was chosen as the inner and outer panel material, with a thickness of $0.2 \mathrm{~mm}$ (the steel was MAT 24 in HyperMesh). As for the aluminum foam core used for the energy absorption material, the thickness should be no less than $6 \mathrm{~mm}$ according to literatures and manufacturers. After numerous experiments, thicknesses in the approximate range of $8 \mathrm{~mm}$ were considered to be appropriate. The properties of each material are shown in Table-4.

The simulation results are shown in Table-5. The curves of acceleration are shown in Fig. 4 (the dotted line represents the AFS, while the solid line represents the original).

\begin{tabular}{cccc} 
& \multicolumn{2}{c}{ TABLE-2 } \\
\hline Pest point & X-Axis & Y-Axis & Meaning \\
\hline AR1 & 57 & -579 & Bonnet side, fire-proof plate and the upper of the hinge \\
AR2 & 149 & -567 & Upper of inner bonnet \\
AR3 & 416 & -278 & Upper of inner bonnet \\
AM1 & 137 & 20 & Bonnet side, the upper of fire-proof plate \\
AM2 & 217 & 220 & Upper of inner bonnet \\
AM3 & 497 & -40 & Bponnet inner, the upper of fire-proof plate \\
AL1 & 142 & 521 & Bonnet side, fire-proof plate and the upper of the hinge \\
AL2 & 75 & 1099 & Upper side of bonnet suspension \\
AL3 & 310 & &
\end{tabular}




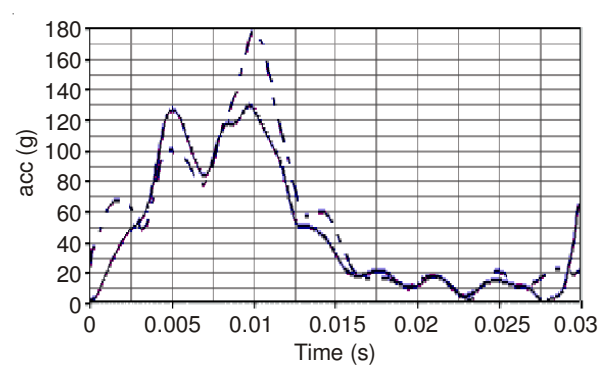

(1) A-R-1

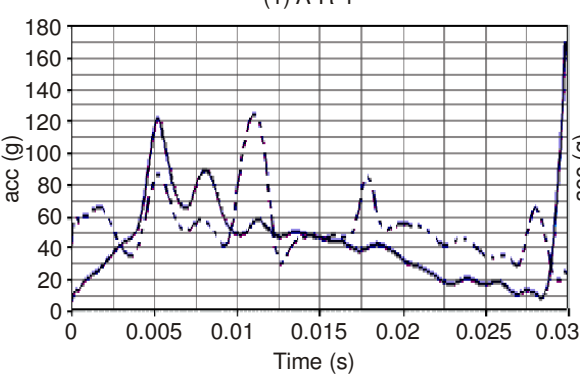

(4) A-M-1

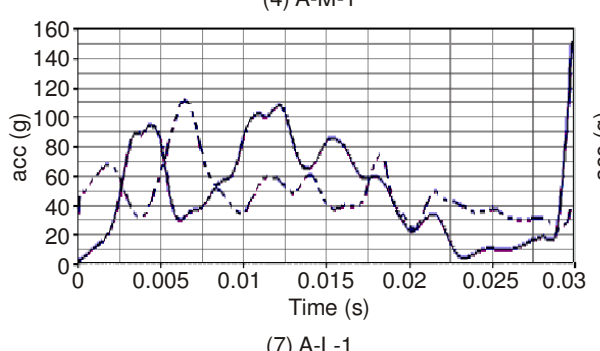

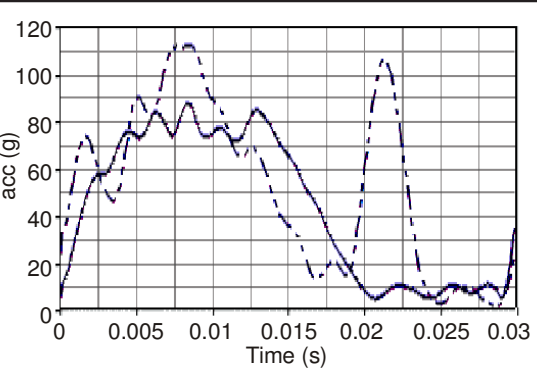

(2) A-R-2

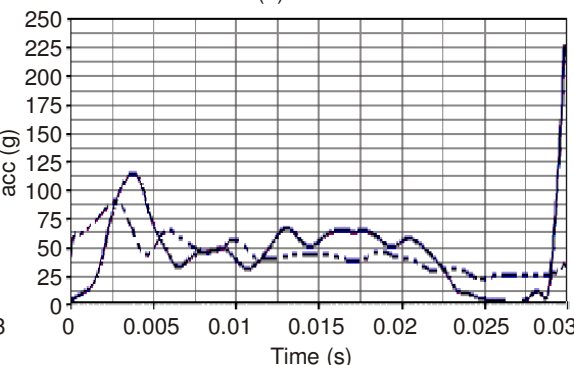

(5) A-M-2

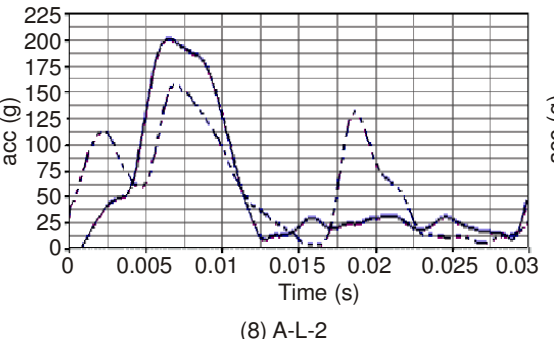

(8) A-L-2

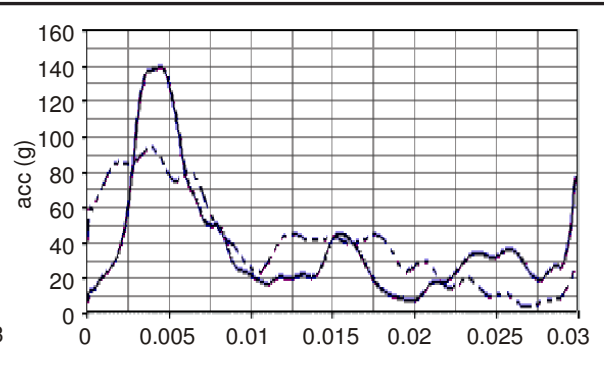

(3) A-R-3

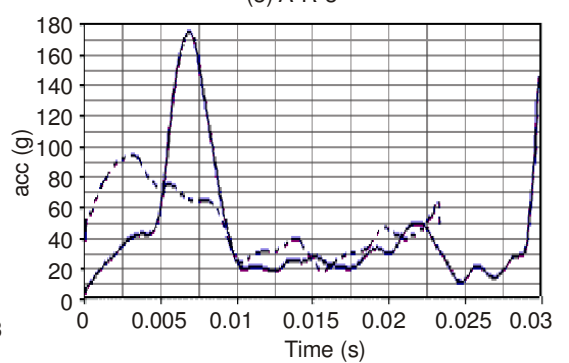

(6) A-M-3

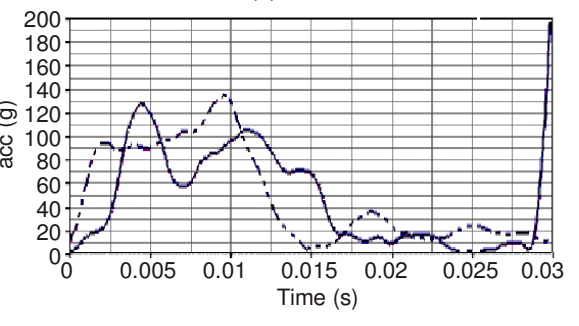

(9) A-L-3

Fig. 4. Comparison of acceleration curves

\begin{tabular}{|c|c|c|c|c|c|c|c|c|c|}
\hline \multicolumn{10}{|c|}{ TABLE-3 } \\
\hline Test point & AR1 & AR2 & AR3 & AM1 & AM2 & AM3 & AL1 & AL2 & AL3 \\
\hline $\mathrm{HIC}$ & 1047 & 688 & 549 & 445 & 432 & 785 & 698 & 2241 & 927 \\
\hline $\mathrm{HIC}_{\mathrm{d}}$ & 956 & 685 & 580 & 502 & 492 & 759 & 693 & 1857 & 865 \\
\hline$a_{\max }(g)$ & 130 & 88 & 140 & 170 & 229 & 176 & 152 & 202 & 198 \\
\hline
\end{tabular}

TABLE-4

PROPERTIES OF EACH BONNET PANEL MATERIALS ${ }^{9}$

\begin{tabular}{cccc}
\hline Material & $\begin{array}{c}\text { Density } \\
\left(\mathrm{g} / \mathrm{cm}^{3}\right)\end{array}$ & $\begin{array}{c}\text { Elasticity } \\
\text { modulus }(\mathrm{GPa})\end{array}$ & $\begin{array}{c}\text { Poisson's } \\
\text { ratio }\end{array}$ \\
\hline Steel & 7.89 & 210 & 0.3 \\
Aluminum foam & 0.56 & 69 & 0.3 \\
\hline
\end{tabular}

It is observed from the above acceleration curves that the peak value of the acceleration was decreased and the wave was weakened when the bonnet was changed to AFS.

The comparison of values in Tables 3 and 5 show that most of $\mathrm{HIC}_{\mathrm{d}}$ values of the test points decreased significantly, but the $\mathrm{HIC}_{\mathrm{d}}$ of test points A-R-1, A-R-2 and A-L-3 still show the potential for serious head injuries. Therefore, impacts with these areas may cause death or injury and necessitate more attention when designing.
Optimization design study of aluminum foam sandwiched bonnet based on design of experiment (DOE): In order to reduce the $\mathrm{HIC}_{\mathrm{d}}$ value and realize a lightweight product, the orthogonal test method was used to further explore the best parameter combination of the AFS bonnet based on above study.

Orthogonal experimental design: The main effect factors included the thickness, the material of the inner and outer bonnet panel and the thickness of the aluminum foam sandwiched. The orthogonal experimental design method was used to analyze these factors. Two levels for each factor were initially chosen to analyze, as shown in Table-6.

To design the experiment, $\mathrm{L}_{4}\left(2^{3}\right)$ was chosen and the orthogonal array is shown in Table-7.

Determination for optimal combination of the bonnet parameters: Using commercial software, 36 impact simul-

\begin{tabular}{ccccccccccc}
\multicolumn{10}{c}{ TABLE-5 } \\
\hline Test point & AR1 & AR2 & AR3 & AM1 & AM2 & AM3 & AL1 & AL2 & AL3 \\
\hline HIC & 1210 & 720 & 408 & 434 & 319 & 413 & 374 & 1120 & 1048 \\
HICd & 1080 & 709 & 474 & 494 & 407 & 478 & 448 & 1011 & 957 \\
HICd & Increase & Increase & Decrease & Decrease & Decrease & Decrease & Decrease & Decrease & Increase \\
$\mathrm{a}_{\max }(\mathrm{g})$ & 176 & 111 & 93 & 123 & 89 & 93 & 110 & 155 & 133 \\
\hline
\end{tabular}


TABLE-6

FACTORS AND LEVELS CONSIDERED IN THE EXPERIMENT

\begin{tabular}{cccc}
\hline Factor & Code & Rank & Number \\
\hline $\begin{array}{c}\text { Thickness of inner and outer } \\
\text { panel }\end{array}$ & $\mathrm{A}$ & $0.2 \mathrm{~mm}, 0.3 \mathrm{~mm}$ & 1,2 \\
$\begin{array}{c}\text { Material of inner and outer } \\
\text { panel }\end{array}$ & $\mathrm{B}$ & Steel, aluminum & 1,2 \\
$\begin{array}{c}\text { Thickness of the aluminum } \\
\text { foam sandwich }\end{array}$ & $\mathrm{C}$ & $8 \mathrm{~mm}, 12 \mathrm{~mm}$ & 1,2 \\
\hline
\end{tabular}

\begin{tabular}{|c|c|c|c|}
\hline \multicolumn{4}{|c|}{$\begin{array}{c}\text { TABLE-7 } \\
\mathrm{L}_{4}\left(2^{3}\right) \text { ORTHOGONAL ARRAY }\end{array}$} \\
\hline Experimental run & $\mathrm{A}$ & B & $\mathrm{C}$ \\
\hline 1 & 1 & 1 & 1 \\
\hline 2 & 1 & 2 & 2 \\
\hline 3 & 2 & 1 & 2 \\
\hline 4 & 2 & 2 & 1 \\
\hline
\end{tabular}

ations were performed according to the four experiment methods described above. The simulati on results are shown in Table-8.

The range analysis method was used to analyze the orthogonal experimental design results primarily to judge the major-minor order, the optimal level and the optimal combination.

The average values of levels 1 and 2 of the three factors were calculated and $\bar{Y}_{j k}(j=A, B, C, k=1,2)$ were used to represent the values. The average value can decide the optimal level of the $\mathrm{j}$ factor. The smaller the average value means the more superior the factor is and the smaller the $\mathrm{HIC}_{\mathrm{d}}$ value.

Range analysis was made with the average values $\overline{\mathrm{Y}}_{\mathrm{j} 1}$ and $\bar{Y}_{j 2}$ of two levels each of factors A, B, C. The resultant expression was $R_{j}=\left|\bar{Y}_{j_{1}}-\bar{Y}_{j_{2}}\right|(j=A, B, C)$. The larger the range was, the more effective the factor and the more influential to the $\mathrm{HIC}_{\mathrm{d}}$. The results of the simulation are shown in Table-9. The optimal combination and the most effective factor of each point are shown in Table-10.

From Table-10, some conclusions about $\mathrm{HIC}_{\mathrm{d}}$ can be drawn: For the reason that the optimal level of all test points was A1, so the level 1 of the A factor was the optimal level. Level B1 was the optimal level of A-R-1, A-M-2, A-L-2 and A-L-3 test points. The range value of levels 1 and 2 was 90.0, 24.2, 9.2 and 21.8, respectively. The difference was small between the four test points. Level B2 was the optimal level of A-R-2, A-R-3, A-M-1, A-M-3 and A-L-1 test points. The range value of Level 1 and 2 was 120.4, 81.8, 50.2, 68.6 and 24.4 , respectively. Therefore, the optimal level of B was level 2. Level $\mathrm{C} 1$ was the optimal level of six test points, $\mathrm{C} 2$ was the optimal level of three test points. The range value of levels 1and 2 of the A-R-1, A-L-2, A-L-3 was 33.6, 17.4, 48.4, respectively and the difference of the $\mathrm{HIC}_{\mathrm{d}}$ value was small. So the

\begin{tabular}{ccccccccccc}
\multicolumn{10}{c}{ TABLE-8 } \\
\hline Number & AR1 & AR2 & AR3 & AM1 & AM2 & AM3 & AL1 & AL2 & AL3 \\
\hline 1 & 1080 & 709 & 474 & 494 & 407 & 478 & 448 & 1011 & 957 \\
2 & 1136 & 637 & 513 & 488 & 501 & 461 & 469 & 1003 & 930 \\
3 & 1161 & 825 & 630 & 713 & 489 & 551 & 514 & 1039 & 959 \\
4 & 1285 & 656 & 427 & 618 & 443 & 430 & 444 & 1066 & 1029 \\
\hline
\end{tabular}

\begin{tabular}{|c|c|c|c|c|c|c|c|c|c|c|c|}
\hline \multicolumn{12}{|c|}{$\begin{array}{c}\text { TABLE-9 } \\
\text { RANGE ANALYSIS }\end{array}$} \\
\hline \multirow{2}{*}{$\begin{array}{l}\text { Test } \\
\text { point }\end{array}$} & \multicolumn{3}{|c|}{ Factor A } & \multicolumn{3}{|c|}{ Factor B } & \multicolumn{3}{|c|}{ Factor $\mathrm{C}$} & \multirow{2}{*}{$\begin{array}{l}\text { Optimal } \\
\text { combination }\end{array}$} & \multirow{2}{*}{$\begin{array}{l}\text { Most effective } \\
\text { factor }\end{array}$} \\
\hline & $\overline{\mathrm{Y}}_{\mathrm{A} 1}$ & $\overline{\mathrm{Y}}_{\mathrm{A} 2}$ & $\mathrm{R}_{\mathrm{A}}$ & $\overline{\mathrm{Y}}_{\mathrm{A} 1}$ & $\overline{\mathrm{Y}}_{\mathrm{A} 2}$ & $\mathrm{R}_{\mathrm{A}}$ & $\overline{\mathrm{Y}}_{\mathrm{A} 1}$ & $\overline{\mathrm{Y}}_{\mathrm{A} 2}$ & $\mathrm{R}_{\mathrm{A}}$ & & \\
\hline AR1 & 1108 & 1223 & 115 & 1120 & 1210 & 90 & 1182 & 1149 & 33 & A1B1C2 & A \\
\hline AR2 & 673 & 740 & 67 & 767 & 647 & 120 & 683 & 731 & 48 & $\mathrm{~A} 1 \mathrm{~B} 2 \mathrm{C} 1$ & B \\
\hline AR3 & 494 & 528 & 34 & 552 & 470 & 81 & 450 & 572 & 121 & $\mathrm{~A} 1 \mathrm{~B} 2 \mathrm{C} 1$ & $\mathrm{C}$ \\
\hline AM1 & 491 & 666 & 174 & 603 & 553 & 50 & 556 & 601 & 44 & $\mathrm{~A} 1 \mathrm{~B} 2 \mathrm{C} 1$ & A \\
\hline AM2 & 454 & 466 & 12 & 448 & 472 & 24 & 425 & 495 & 69 & $\mathrm{~A} 1 \mathrm{~B} 1 \mathrm{C} 1$ & $\mathrm{C}$ \\
\hline AM3 & 470 & 491 & 21 & 514 & 446 & 68 & 454 & 506 & 51 & A1B2C1 & B \\
\hline AL1 & 459 & 479 & 20 & 481 & 457 & 24 & 446 & 492 & 45 & $\mathrm{~A} 1 \mathrm{~B} 2 \mathrm{C} 1$ & $\mathrm{C}$ \\
\hline AL2 & 1007 & 1053 & 45 & 1025 & 1034 & 9 & 1038 & 1021 & 17 & A1B1C2 & A \\
\hline AL3 & 944 & 994 & 50 & 958 & 980 & 21 & 993 & 944 & 48 & $\mathrm{~A} 1 \mathrm{~B} 1 \mathrm{C} 2$ & A \\
\hline
\end{tabular}

\begin{tabular}{|c|c|c|c|c|c|c|c|}
\hline \multicolumn{8}{|c|}{$\begin{array}{c}\text { TABLE-10 } \\
\text { RESULTS ANALYSIS }\end{array}$} \\
\hline Test point & A1 & $\mathrm{A} 2$ & B1 & B2 & $\mathrm{C} 1$ & $\mathrm{C} 2$ & Most effective factor \\
\hline A-R-1 & $\sqrt{ }$ & - & $\sqrt{ }$ & - & - & $\sqrt{ }$ & $\mathrm{A}$ \\
\hline A-R-2 & $\sqrt{ }$ & - & - & $\sqrt{ }$ & $\sqrt{ }$ & - & B \\
\hline A-R-3 & $\sqrt{ }$ & - & - & $\sqrt{ }$ & $\sqrt{ }$ & - & $\mathrm{C}$ \\
\hline A-M-1 & $\sqrt{ }$ & - & - & $\sqrt{ }$ & $\sqrt{ }$ & - & A \\
\hline A-M-2 & $\sqrt{ }$ & - & $\sqrt{ }$ & - & $\sqrt{ }$ & - & $\mathrm{C}$ \\
\hline A-M-3 & $\sqrt{ }$ & - & - & $\sqrt{ }$ & $\sqrt{ }$ & - & B \\
\hline A-L-1 & $\sqrt{ }$ & - & - & $\sqrt{ }$ & $\sqrt{ }$ & - & $\mathrm{C}$ \\
\hline A-L-2 & $\sqrt{ }$ & - & $\sqrt{ }$ & - & - & $\sqrt{ }$ & A \\
\hline A-L-3 & $\sqrt{ }$ & - & $\sqrt{ }$ & - & - & $\sqrt{ }$ & A \\
\hline Total times & 9 & 0 & 4 & 5 & 6 & 3 & A-4 times, B-2 times, C-3 times \\
\hline
\end{tabular}




\begin{tabular}{|c|c|c|c|c|c|c|c|c|c|}
\hline Test point & AR1 & AR2 & AR3 & AM1 & AM2 & AM3 & AL1 & AL2 & AL3 \\
\hline HIC of original car & 1047 & 688 & 549 & 445 & 432 & 785 & 698 & 2241 & 927 \\
\hline $\mathrm{HIC}_{\mathrm{d}}$ of original car & 956 & 685 & 580 & 502 & 492 & 759 & 693 & 1857 & 865 \\
\hline HIC of new car & 1001 & 609 & 310 & 239 & 307 & 329 & 381 & 1168 & 987 \\
\hline $\mathrm{HIC}_{\mathrm{d}}$ of new car & 937 & 626 & 400 & 347 & 398 & 415 & 456 & 1048 & 920 \\
\hline Change of $\mathrm{HIC}_{\mathrm{d}}$ & Decrease & Decrease & Decrease & Decrease & Decrease & Decrease & Decrease & Decrease & Increase \\
\hline
\end{tabular}

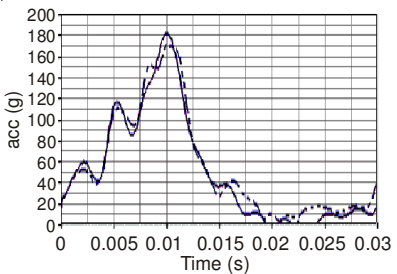

(1) A-R-1

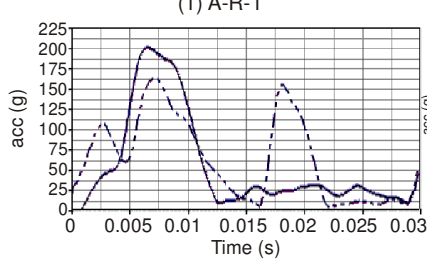

(4) A-M-1

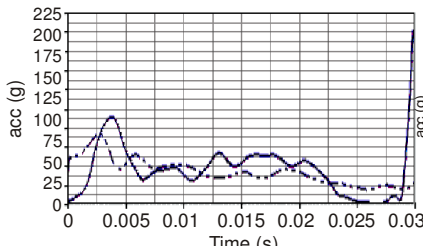

(7) A-L-1

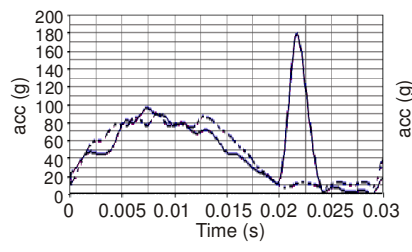

(2) A-R-2

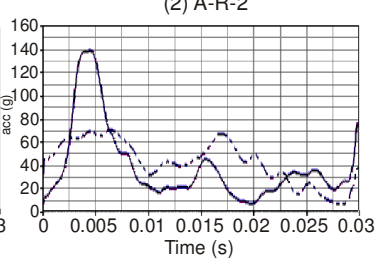

(5) A-M-2

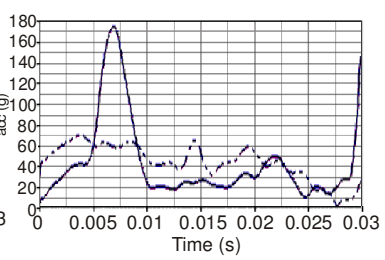

(8) A-L-2

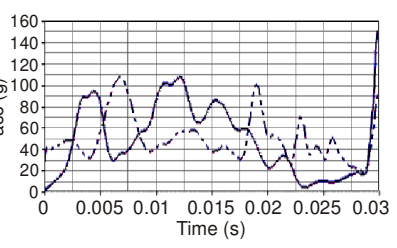

(3) A-R-3

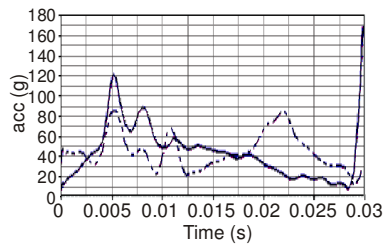

(6) A-M-3

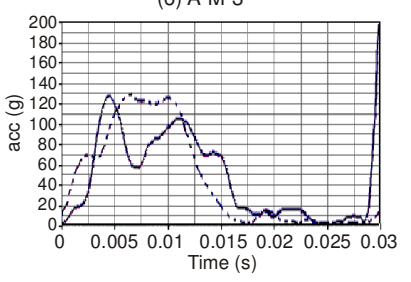

(9) A-L-3

Fig. 5. Comparison of original car and modified car acceleration curves

optimal level of the $\mathrm{C}$ factor was level 1. To sum up, the optimal combination of bonnet parameters was A1B2C1.

Verification: From the above information, it can be confirmed that the optimal combination is $\mathrm{A} 1 \mathrm{~B} 2 \mathrm{C} 1$ and this combination did not belong to the four cases in the orthogonal experimental design. This showed that the optimal results represented the information obtained in the experiments and the orthogonal design method can be adopted to optimize the bonnet.

The thickness of the outer panel was changed to $0.2 \mathrm{~mm}$ and it was simulated again. The results are shown in Table- 11 . The comparison of the acceleration curves are shown in Fig. 5.

From Table-11 and Fig. 5, it can be seen that parameters A1B2C1 decreased the $\mathrm{HIC}_{\mathrm{d}}$ significantly and the wave of acceleration was also weakened. This optimal combination was proved effective.

Weight analysis of the aluminum foam sandwiched bonnet: The HyperMesh has a function that counts component mass. Compared to the original bonnet, the mass of the AFS bonnet decreased from $21.42-8.524 \mathrm{~kg}$ because of the low density of the aluminum foam, therefore achieving the goal of being lightweight. It can also improve fuel efficiency and decrease energy consumption.

\section{Conclusion}

Using HyperMesh, the original bonnet material was changed to aluminum foam sandwiched and LS-DYNA was used to simulate the impact progress. The pedestrian head protection effect of the new bonnet was studied. Compared to the original bonnet, the simulation results showed that the aluminum foam sandwiched bonnet had a better effect on pedestrian protection. The optimal combination of the aluminum foam sandwiched bonnet was attained for pedestrian head protection through orthogonal experimental design methods. And by mass analysis, the low-weight effect was improved effectively. The research results in this paper can provide a certain theoretical basis for the application of new materials in vehicles, especially in terms of pedestrian protection and reducing vehicle weight.

\section{REFERENCES}

1. D. Liu, Y.D. Li and H. Zhao, Trans. Chinese Soc. Agric. Machinery, 34 (2003).

2. W.G. Qiao, X.C. Zhu and Z.F. Wang, Trans. Chinese Soc. Agric. Machinery, 36 (2005).

3. S.I. Farooq and P.J. Schuster, SAE paper, 2003-01-1300 (2003).

4. D. de Melo Baleki and A. Ferreira, SAE Technical Papers, 2009-360093 (2009).

5. Z.L. Wu, X.X. Xu and L. Liu, Transport. Sci. Technol., 4 (2008).

6. P.P. Wang and Y.H. Yu, Coal Mine Machinery, 11 (2003).

7. European Enhanced Vehicle-safety Committee (EEVC) Working Group 17 Report, Improved Test Methods to Evaluate Pedestrian Protection Afforded by Passenger Cars (2002).

8. European Enhanced Vehicle-Safety Committee, EEVC Working Group 10 Reports-Proposals for Methods to Evaluate Pedestrian Protection Afforded by Passengers Cars, Delft, the Netherlands: TNO Crash-Safety Research Centre (1994).

9. P. Wei, Doctoral Thesis, Huazhong University of Science and Techno$\log$ (2006). 